\title{
The Impact of Push Phases Takeoffs Angles on Performance in the Dominant Hop Technique
}

\author{
Zerf Mohammed \\ Physical Education Institute Laboratory OPAPS, University of Mostaganem, Mostaganem, Algeria \\ Email: biomeca.zerf@outlook.com
}

Received 1 November 2015; accepted 19 November 2015; published 24 November 2015

Copyright (C) 2015 by author and OALib.

This work is licensed under the Creative Commons Attribution International License (CC BY). http://creativecommons.org/licenses/by/4.0/

(c) (i) Open Access

\begin{abstract}
The purposes of this study were to compare the technique dominant hop used by elite world triple jumper to determine the impact of modality angles push phases allowing the elite to exceed 17-meter. Bing Yu (1982) confirmed that, any athlete came to the typical (39\%:30\%:31\%) ratio distribution as big performance in the hop phase as modality to the Russian technique (which emphasizes the hop phase). From that our subjects were the results of (Idowu P. 3rd, Copello A. 6th) World Athletics Championships 2009 and their results at the World Athletics Championships 2011 (Idowu P. 4th, Copello A. 5th), where our elites of world championships practiced the hop dominant technique as technique in the two competitions. In the lack of new technology, modern measuring instruments kinematics or kinetics. Our study was based on rapports take-off angels as measure of stride length jump distance based on the results of the practice (the same elites and the same technique). After statistical treatment, we confirm that: 1) the take-offs angels push phases are a criterion mean to assess and judge the level of application of elite; 2 ) any less change take-offs angels pushes in step phase change the angular momentum created by hop phase.
\end{abstract}

\section{Keywords}

Push Phases Takeoffs Angles, Performance, Dominant Hop Technique

Subject Areas: Kinesiology, Sports Science

\section{Introduction}

The triple jump is one of three jumping events in track and field. The literature review by Abeer Eissa (2014) [1] confirmed that the triple jump consists of a running approach, 3 take-off phases in which the athlete hops on one foot, lands on the same foot, steps onto the opposite foot, and finally jumps and lands in the sand pit. Bing Yu 
and James G. Hay and John A. Miller, Jr. 1985 [2] explain the difficulty in the involvement of the three consecutive touchdowns and takeoffs at high speed and a change in the support leg; from that the triple jump is technically more demanding than other jumps. Form this they conclude that the take-off of the step should be obtained, which [3] Gordon Robertson (2004) confirms that any less change in the step phase changes the angular momentum created by hop phase. Based on the confirmation of Hui Liu (2012) [4] that the phase ratio is a measure of effort distribution in the triple jump (hop-dominant, balanced, and jump-dominant techniques), where the three techniques are defined based on phase ratio which [5] Bing Yu (1982) set that nearly no one came to the 39\%:30\%:31\% ratio in the practice of the Russian technique.

Our goal came to introduce the biomechanics evaluation before explaining the reason scientific of the importance of maintaining the model take-off angel's push phases applied in the outcome.

In addition, our research analyzes the performance of world elites as modality to illustrate the importance of the good impact of the relationship of take-offs angels pushes phases with the final results in triple jump. Our motive is to highlight the biomechanical assessment for our Algerian coaches to plan the choice of the right assessment technique to their athletes [6]. We rely on the interpretation of [7] Boo Schexnayder (2014) executing that the step phase is a physical challenge. Tremendous vertical forces must be generated in the fraction of a second; the foot is in contact with the ground. This difficult task demands training. Our study is based on the rapports take-offs angels as measure of Stride length Jump distance of world elite 2009 from the [7] project by the German athletics federation and world elite 2011 from the Korean Society of Sport Biomechanics [8]. To verify the hypothesis that supports:

The reasons of the weakness in the Russian technique (which emphasizes the hop phase) are the optimization going forward and up and the less change in the step phase that changes the angular momentum created by hop phase.

From that, our aims for this study interest:

1) Are there any statistically significant difference in Pushes Phases Takeoffs Angles between our samples (the same elites and the same technique) in the two competitions (world 2009 - world elite 2011)?

2) Are there any causal relationships of Pushes Phases Takeoffs Angles with the Finale Results between our samples (the same elites in the hop technique) in the two competitions (world 2009 - world elite 2011)?

For that, we have chosen the analysis of the regression variance and correlation of Push Phases Takeoffs Angles and distances achieved in each of their phases. With the official distance of the jumper, and the Paired Samples Test, we compare implementations of Pushes Phases Takeoffs Angles and the distribution of phases (hop, step and jump) with the results attended and limits of the study.

\section{Material and Methods}

For the purposes of analysis, we have explore the report IAAF (International Association of Athletics Federations) indicate in the references of Project by the German Atletecs Federration (2009) [8] and (Young-Sang Bae, Young-Jin Park, Jong-Jin, Park, Joong-Sook, Lee, Woen-Sik, Chae, Seung-Bum, Park (2011) [9] as repair to Extraction Angle of take-off ( ${ }^{\circ}$ ) push phases for our samples. For the experimental conditions, we have taken the results of the contestants in the two competitions (2009-2011) with the above-mentioned application of the same distribution model.

\section{Data Collection}

\subsection{Subjects}

The subjects were the two-world champions (Idowu P. 3rd, Copello A. 6th) Berlin 2009 results from the project by the German Athletics Federation (2009) and world elite 2011, where our two elites practiced the hop dominant technique as technique in the two World Athletics Championships.

Through data drawn in the Table 1(a), Table 1(b). The Results (a) Champions World (2009-2011) and selection of same athlete's results competitor, we have calculated relative dist.

From the Table 1(a), Table 1(b) as the Search limits, we confirms that the dominant Techniques is in the benefit of the Hop-dominated, based in the Mean of the lengths three phases we observed that they are typically (35\% 32\% 33\%) in 2009 and (37\% 31\% 32\%) in 2011. From its results, aware find Approved with confirmation of McNab (1968) [10], Bing Yu, PhD (1982) [10] and S.J. Allen (2013) [11]: 
Table 1. Description of the acquired results of our samples.

\begin{tabular}{|c|c|c|c|c|c|c|c|c|c|c|}
\hline \multirow{3}{*}{ Variables } & \multicolumn{10}{|c|}{ The Results (a) Champions World 2009} \\
\hline & \multirow{2}{*}{$\begin{array}{c}\text { Real } \\
\text { Distance }\end{array}$} & \multicolumn{3}{|c|}{ Stride length $[\mathrm{m}]$} & \multicolumn{3}{|c|}{ Angle of take-off $\left({ }^{\circ}\right)$ pivot phases } & \multicolumn{3}{|c|}{ Relative dist. [\%] } \\
\hline & & Hop & Step & Jump & Нор & Step & Jump & Hop & Step & Jump \\
\hline Idowu P. 3rd & 17.92 & 6.49 & 5.41 & 6.02 & 14 & 13 & 21 & 36 & 30 & 34 \\
\hline Copello A. 6th & 17.54 & 6.01 & 5.77 & 5.92 & 13 & 15 & 20 & 34 & 33 & 33 \\
\hline Mean & 17.73 & 6.25 & 5.59 & 5.97 & 13.5 & 14 & 20.5 & 35 & 32 & 33 \\
\hline SD & 0.27 & 0.34 & 0.25 & 0.07 & 0.71 & 1.41 & 0.71 & 1.57 & 1.91 & 0.42 \\
\hline \multirow{3}{*}{ Variables } & \multicolumn{10}{|c|}{ The Results (b) Champions World 2011} \\
\hline & Real & \multicolumn{3}{|c|}{ Stride length [m] } & \multicolumn{3}{|c|}{ Angle of take-off $\left({ }^{\circ}\right)$ pivot phases } & \multicolumn{3}{|c|}{ Relative dist. [\%] } \\
\hline & Distance & Hop & Step & Jump & Нор & Step & Jump & Hop & Step & Jump \\
\hline Idowu P. 4th & 17.77 & 6.67 & 5.64 & 5.60 & 12.6 & 14.3 & 21.8 & 37 & 32 & 31 \\
\hline Copello A. 5th & 17.62 & 6.40 & 5.38 & 5.84 & 14.1 & 14.6 & 21.3 & 36 & 31 & 33 \\
\hline Mean & 17.70 & 6.54 & 5.51 & 5.72 & 13.35 & 14.45 & 21.55 & 37 & 31 & 32 \\
\hline SD & 0.11 & 0.19 & 0.18 & 0.17 & 1.06 & 0.21 & 0.35 & 0.48 & 0.85 & 1.52 \\
\hline
\end{tabular}

That the Hop Phases are the largest of the other Phases in comparison with it representation ratios depending on the distribution of the total distance that explained the partied of the Russian technique (which emphasizes the hop phase) [12].

\subsection{Data Analysis}

Based on the same tests of our champions in the two competitions our data analysis procedures used in this study consisted of the computation of the means, standard deviations, the Regression and Paired Samples Test of all the variables identified in based of the theoretical model in the similar studies. For the data collected, and the computation the Pearson product-moment correlations between each of these variables with the official distance of the triple jump. To identify important associations among the independent variables in official distance of the jump (Figure 1).

\section{Results and Discussion}

From the Table 2 through the results of the paired T student and paired correlation of the variables of our samples, at the 0.05 level (2-tailed) and Degrees of freedom $(n-1)$ that the T calculated is not significant Within All comparisons. Inverse Paired Samples Correlations calculated is significant Within All comparisons. Except with the hop phase that is strong negative.

\section{Conclusion 1}

Through Table 2 and account for paired T student and paired correlation. Differences recorded in the two competitions due to hop phase where the deference of the relative distance hop [\%] between the two competitions is 2\%. That Paul Brice (2009) [13] explains in the objective of this phase, the achievement horizontal vertical velocity (going forward and up) of the takeoff board. That Gordon Robertson (2004) [3] set that any should minimally in the step phase change the angular momentum created by hop. Where our find approved with confirmation of Bing Yu and James G. Hay requires that the takeoff of the step should be obtained. That we conclude in Figure 2.

From the Figure 2, we observe that the decrease of step distance phase and the increase of the hop phase contributes on the increase of the final real distance [12]. Which confirms the diagnosis of Bing Yu (1982) [5] that, 


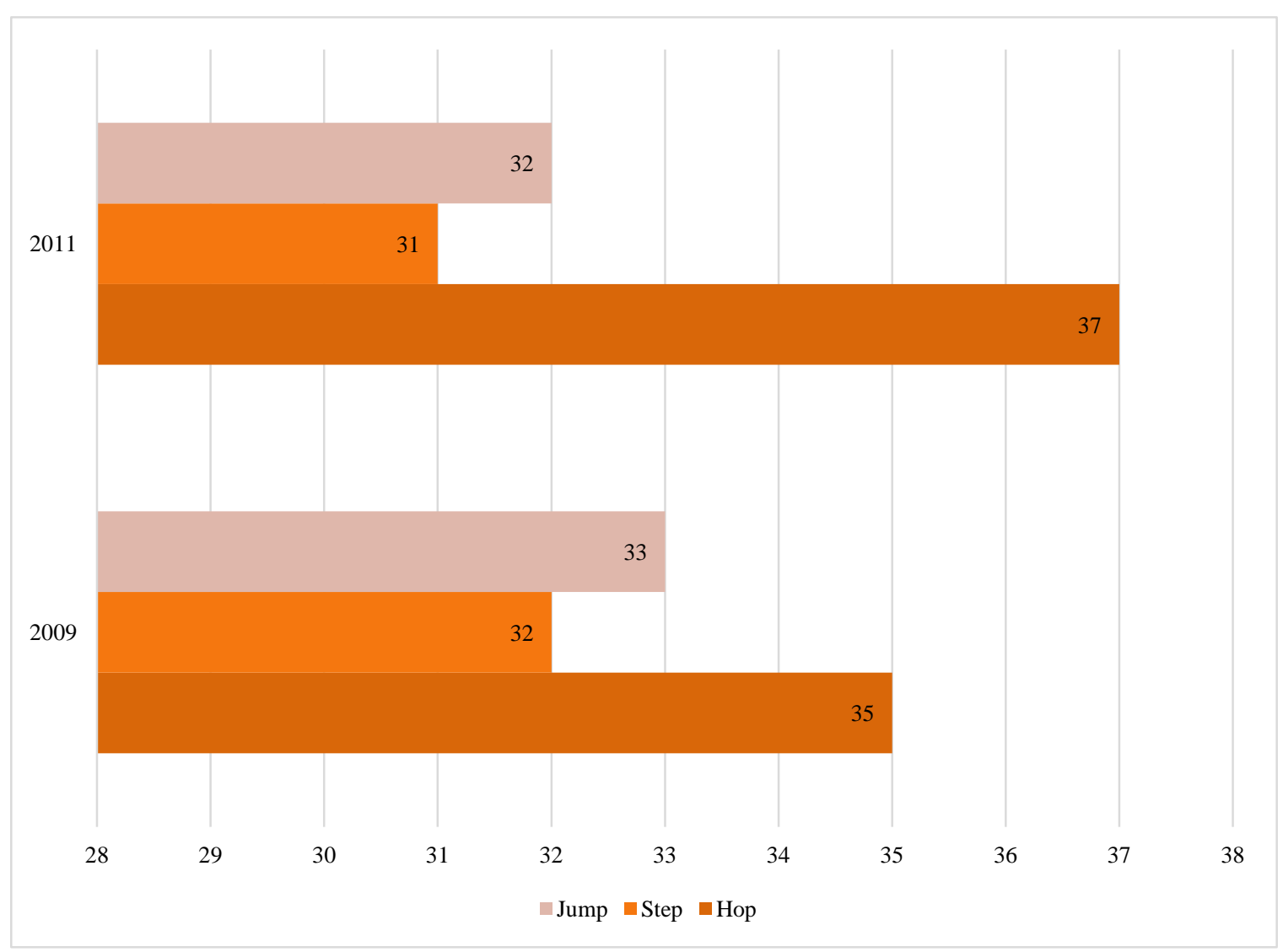

Figure 1. Shows the comparison of the relative distance. [\%] Between the two competitions.

Table 2. With deference statistical existed between take-off angels push phases between our samples in the two competitions (world 2009 - world elite 2011).

\begin{tabular}{|c|c|c|c|c|c|c|c|}
\hline Variables & & Mean & SD & $\mathbf{t}$ & df & $\mathbf{R}$ & Sig. (2-tailed) \\
\hline \multirow{3}{*}{ Hop take-off angels } & 2009 & 13.00 & 0.71 & \multirow{3}{*}{0.120} & \multirow{6}{*}{01} & \multirow{3}{*}{-1} & \multirow{3}{*}{0.924} \\
\hline & & & & & & & \\
\hline & 2011 & 13.35 & 1.06 & & & & \\
\hline \multirow{3}{*}{ Step take-off angels } & 2009 & 5.76 & 1.41 & \multirow{3}{*}{-0.529} & & \multirow{3}{*}{+1} & \multirow{3}{*}{0.690} \\
\hline & & & & & & & \\
\hline & 2011 & 5.41 & 0.21 & & & & \\
\hline \multirow{3}{*}{ Jump take-off angels } & 2009 & 5.06 & 0.71 & \multirow{3}{*}{-4.20} & & \multirow{3}{*}{+1} & \multirow{3}{*}{0.149} \\
\hline & & & & & & & \\
\hline & 2011 & 5.85 & 0.35 & & & & \\
\hline
\end{tabular}

any athlete came to the typically (39\%:30\%:31\%) ratio distribution as big Performance in the hop phase as modality to the Russian technique (which emphasizes the hop phase).

We chose Regression as a model in statistics.

From the Table 3(a) we note that the regression method, which is, used in a manner model 1, is the Stepwise where the program has shown that it introduces only the Step Angle of take-off $\left(^{\circ}\right)$ as the independent variable in the equation of multiple linear regression.

Table 3(b), we note that the three values of the simple correlation and the coefficient (R Square-Adjusted R Square), are significant in the Predictors used in Model 1. From that, we confirmed the independent explanatory variables Step Angle of take-off $\left({ }^{\circ}\right)$ was able to explain the changes in the Dependent Variable Jump distance in practiced technique Hop dominate that is required and the rest (0.04) is attributable to other factors.

As it is noted in Table 3(c) of the variables Predictor include in analysis to define the explanatory power of 


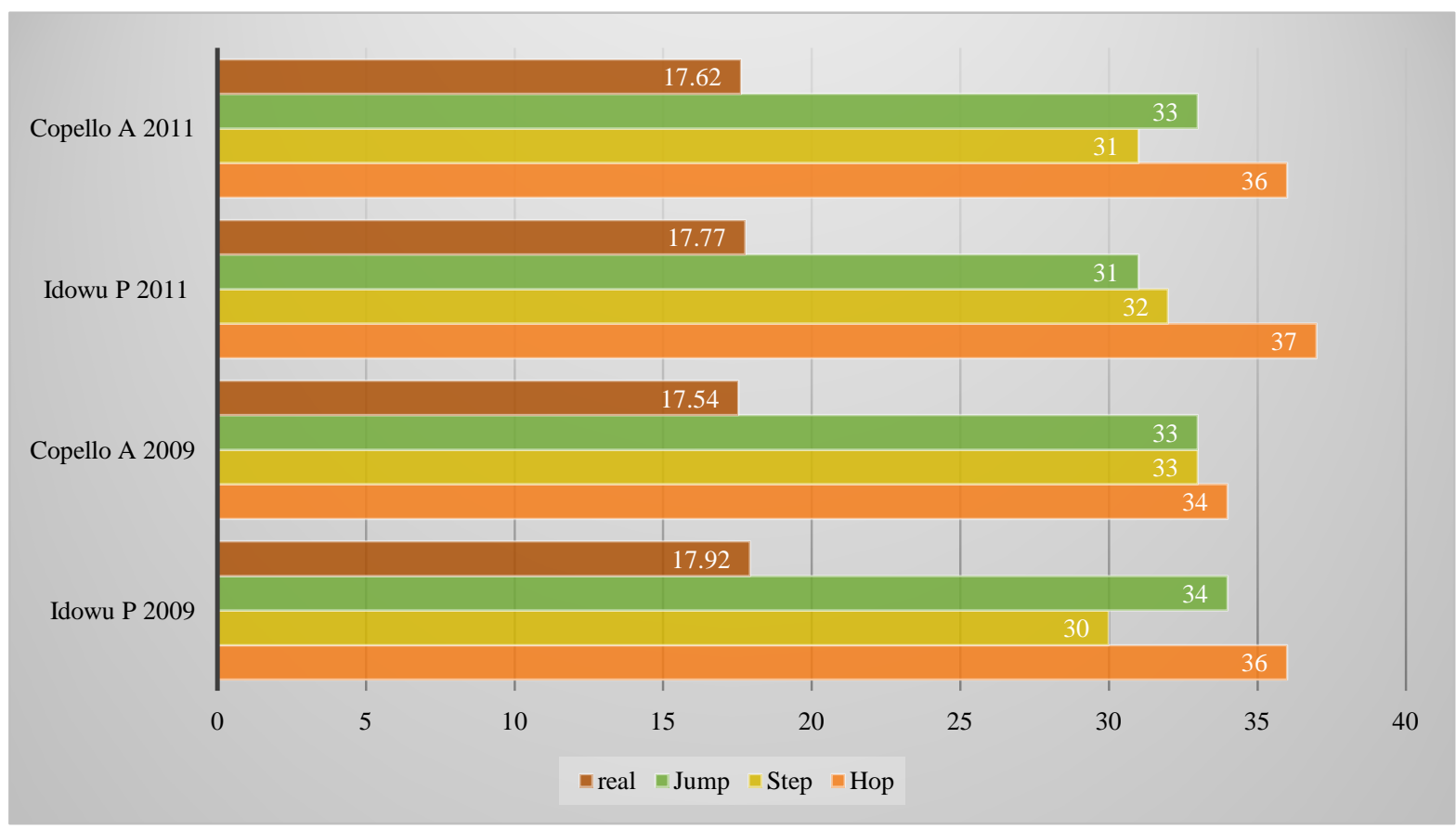

Figure 2. Shows effect of distribution hop and the phase step on the final result in the two competitions.

the model 1 based by the value of $\mathrm{F}$. As can be seen from the High explanatory power of multiple linear regression model from a statistical point the $\mathrm{F}$ test High moral $(\mathrm{P}<0.04)$, from that we confirms the High moral explanatory power of the model chosen of the multiple linear regression statistical.

We conclude from the Table 3(d) that the independent variable was significant from a statistical point of these tests that we confirmed by $\mathrm{t}$ (at the moral level of $\mathrm{P} \leq 0.04$ ) in all comparisons, which it is the Reason, explanatory power of the moral analysis of variance Regression. From that our equation

$$
\text { Regression line Jump distance }=20.360-0.186 \text { Step Angle of take-off }\left(^{\circ}\right)
$$

We conclude from the Tables 3(a)-(d) that the Hop dominated technique practiced as distributions ratios is dependent with the particle of the independent distance of Step Angle of take-off $\left(^{\circ}\right)$.

Where any change in the objective of hop phase to achieve horizontal vertical velocity (going forward and up) [13] of the takeoff board is transmit in the step phase that Gordon Robertson (2004) confirms for any should minimally in the step phase change the angular momentum created by hop. That Bing Yu and James G. Hay consist that the takeoff of the step should be obtained [14].

\section{Discussion and Conclusion of Our Experience}

The study showed the nearest and the causes that, any came to the 39\%:30\%:31\% ratio in the practice of the Russian technique (which emphasizes the hop phase) and the uses by our samples [4]. The most difference between our samples are in relationship errors transmitted by the hop in the step phase that Paul Brice explain in the objective of this phase is to achieve horizontal vertical velocity (going forward and up) of the takeoff board, not vertical horizontal velocity (up and forward as in the long jump), for the cause where Gordon Robert (2004) confirms that any should minimally in the step phase change the angular momentum created by hop [15].

For beer Elisa [1] the change in the influential bio-mechanic indicator values (horizontal velocity loss, vertical velocity, take-off angels, time of braking and pushing) the run the hop the step and the jump performed by elite in highly competitive situation.

For our research, we explain it by the good mastery of the Owner best result in the optimization of the Push Phases Takeoffs Angles and the transition of their phases that any errors are transmitted to other that [16] Ed Jacoby (2009) explain: the good phase transmission is the key to a better jump in triple jump for our study, the defeat technique modality is related to the distribution of phase's efforts and the importance of Step Angle 
Table 3. Which causal relationship take-off angel's push phases are with the finale results between our samples in the two competitions (world 2009 - world elite 2011).

\begin{tabular}{cccc}
\hline & & (a) Variables Entered/Removed ${ }^{\mathrm{a}}$ & \\
\hline Model & Variables Entered & Variables Removed & Method \\
\hline 1 & Step angle of take-off $\left(^{\circ}\right)$ & $\begin{array}{c}\text { Stepwise (Criteria: Probability-of-F-to-enter } \\
<=0.050 \text {, Probability-of-F-to-remove }>=0.100) .\end{array}$ \\
\hline
\end{tabular}

a. Dependent variable: jump distance.

\begin{tabular}{|c|c|c|c|c|c|c|c|c|c|c|}
\hline \multicolumn{11}{|c|}{ (b) Model Summary } \\
\hline \multirow{2}{*}{ Model } & \multirow{2}{*}{$\mathrm{R}$} & \multirow{2}{*}{$\begin{array}{c}\mathrm{R} \\
\text { Square }\end{array}$} & \multirow{2}{*}{$\begin{array}{l}\text { Adjusted } \\
\text { R Square }\end{array}$} & \multirow{2}{*}{$\begin{array}{l}\text { Std. Error of } \\
\text { the Estimate }\end{array}$} & \multicolumn{5}{|c|}{ Change Statistics } & \multirow{2}{*}{ Durbin-Watson } \\
\hline & & & & & R Square Change & F Change & df1 & df2 & Sig. F Change & \\
\hline 1 & $0.96^{\mathrm{a}}$ & 0.92 & 0.88 & 0.059 & 0.92 & 22.76 & 1 & 2 & 0.041 & 2.76 \\
\hline
\end{tabular}

a. Predictors: (constant), step angle of take-off $\left(^{\circ}\right)$; b. Dependent variable: jump distance.

\begin{tabular}{|c|c|c|c|c|c|c|}
\hline \multicolumn{7}{|c|}{ (c) $\mathrm{ANOVA}^{\mathrm{a}}$} \\
\hline & Model & Sum of Squares & df & Mean Square & $\mathrm{F}$ & Sig. \\
\hline \multirow{3}{*}{1} & Regression & 0.078 & 1 & 0.078 & 22.757 & $0.041 b$ \\
\hline & Residual & 0.007 & 2 & 0.003 & & \\
\hline & Total & 0.085 & 3 & & & \\
\hline
\end{tabular}

a. Dependent variable: jump distance; b. Predictors: (constant), step angle of take-off $\left({ }^{\circ}\right.$ ).

\begin{tabular}{|c|c|c|c|c|c|c|}
\hline \multicolumn{7}{|c|}{ (d) Coefficients ${ }^{\mathrm{a}}$} \\
\hline & \multirow{2}{*}{ Model } & \multicolumn{2}{|c|}{ Unstandardized Coefficients } & \multirow{2}{*}{$\begin{array}{c}\text { Standardized Coefficients } \\
\text { Beta }\end{array}$} & \multirow{2}{*}{$\mathrm{t}$} & \multirow{2}{*}{ Sig. } \\
\hline & & B & Std. Error & & & \\
\hline \multirow{2}{*}{1} & (Constant) & 20.360 & 0.556 & & 36.639 & 0.001 \\
\hline & Step angle of take-off $\left({ }^{\circ}\right)$ & -0.186 & 0.039 & -0.959 & -4.770 & 0.041 \\
\hline
\end{tabular}

a. Dependent variable: jump distance.

take-off $\left({ }^{\circ}\right)$. That Hay (1992) explain in Effort distribution decides jumping techniques in different phases especially in the hop and step phases [17] [18].

For our coach and their elites we recommended the Modern measuring instruments kinematics and kinetics [12] to improve the impact of the momentum needed at the takeoff of the step that it should be obtained during the support phase of the hop and any less change in the side-somersaulting angular momentum during the support phase of the step should be minimized. And from another side, we rely on the interpretation of Ryu, Jae-Kyun (2004) [19] the impact of the actions of the arms created a side-somersaulting angular momentum about the whole body center of gravity toward the side of the free leg during the support phase of the step, and a somersaulting angular momentum about the whole body center of gravity during each support phase. The action of the free leg created a somersaulting angular momentum about the whole body center of gravity during the support phases of the hop and step and as a practical recommendation, we recommended instructions of (Boo Schexnayder, 2014) [7] executing the step phase is a physical challenge. Tremendous vertical forces must be generated in the fraction of a second the foot is in contact with the ground. This difficult task demands training [11] [15].

\section{Our Results and Recommendation}

1) That the take-off angels push phases is a criterion mean to assess and judge the level of application of elite.

2) Any take-off angels push phases less change in the step phase change the angular momentum created by hop phase. 
3) The transition of the error in achieve horizontal vertical velocity in hop phase are related in the other phases.

\section{Our Aim}

\section{For the national elites and their technical steps:}

- Using the biomechanics to determine errors in practicing the theoretical models of the sports tricks.

- Integrating the modern scientific methods into the program monitoring sports.

- Studying the problem posed in other similar studies.

- Taking advantage of this study in the assessment and training triple jump.

\section{References}

[1] Eissa, A. (2014) Biomechanical Evaluation of the Phases of the Triple Jump Take-Off in a Top Female Athlete. Journal of Human Kinetics, 40, 29-35. http://dx.doi.org/10.2478/hukin-2014-0004

[2] Hay, J.G. and Miller, Jr., J.A. (1985) Techniques Used in the Triple Jump. Journal of Applied Biomecanics, 1, 185196.

[3] Robertson, G., et al. (2014) Research Methods in Biomechanics. 2nd Edition, Human Kinetics, USA, 92.

[4] Liu, H. and Yu, B. (2012) Effects of Phase Ratio and Velocity Conversion Coefficient on the Performance of the Triple Jump. Journal of Sports Sciences, 14, 36. http://dx.doi.org/10.1080/02640414.2012.713502

[5] Yu, B. (1982) Biomechanics of Triple Jump. Ph.D. Thesis, Center for Human Movement Science, The University of North Carolina at Chapel Hill, Chapel Hill.

[6] Ahmed, A. and Mohammed, Z. (2015) A Study of Some Mechanical Focal Stages in the Triple Jump and Their Relationship with Performance. The 1st International Congress of I3SAW, 68.

[7] Schexnayder, B. (2015) Fixing the Second Phase in the Triple Jump.

[8] German Athletics Federation (2009) Biomechanics Report WC Berlin 2009 Triple. German Atletecs Federration, German.

[9] Bae, Y.-S., Park, Y.-J., Park, J.-J., Lee, J.-S., Chae, W.-S. and Park, S.-B. (2011) Biomechanics Research Project in the IAAF World Championships in Athletics-Daegu. IAAF World Championships Daegu 2011, Korean Society of Sport Biomechanics (KSSB) and Japan Association.

[10] McNab, T. (1968) Triple Jump. Amateur Athletic Association, London.

[11] Allen, S.J., King, M.A. and Yeadon, M.R. (2013) Trade-Offs between Horizontal and Vertical Velocities during Triple Jumping and the Effect on Phase Distances. Journal of Biomechanics, 15, 979-983. http://dx.doi.org/10.1016/j.jbiomech.2012.12.011

[12] Mohammed, Z. (2015) The Impact of the Three Pushes Takeoffs Angel's Phases and Their Distributions Strides Lengths on the Performance in Triple Jump. International Journal of Modern Trends in Engineering and Research (IJMTER), 2, 317-323.

[13] Brice, P. (2009) Using Quintic Biomechanics to Calculate Centre of Mass. Q4E Case Study, p. Sport Science (AS/A level /1st Year Degree Level).

[14] Mohammed, Z., Idriss, M.M. and Hassiba, D. (2015) Impact of the Distribution Ratio Properties in the Evaluation of the Technique Triple Jump Theoretical Technique. International Journal of Novel Research in Humanity and Social Sciences, 2, 1-15.

[15] Mohammed, Z., Idris, M.M., Ali, B. and Nasreddin, B.M. (2015) Influence Technique vs Ideal Model on Credibility Theory Distributions Ratios: A Case Study of Triple Jump. European Scientific Journal, 11, 334-346.

[16] Jacoby, Ed (2009) Winning Jumps and Pole Vault. Human Kinetics, USA, 43.

[17] Mohammed, Z., Idriss, M.M., Ali, B., Nasreddin, B.M. and Abd-el-Kader, G. (2015) The Impact of the Techniques and Tactics Appropriate by the Athletes in Phase Triple Jump and Their Relationships with the Finale Results. Journal of Sports Science, 3, 179-185.

[18] Mohammed, Z., Idris, M.M., Ali, B. and Nasreddin, B.M. (2015) Which Causal Relationships Can Reject or Accept the Significant Optimum Distribution Ratios Phases in the Triple Jump. American Journal of Sports Science, 3, 73-78. http://dx.doi.org/10.11648/j.ajss.20150304.12

[19] Ryu, J.-K. and Yeo, H.-C. (2004) The Relationship between the Angular Momentum of the Limbs and the Performance during Support Phase of the Triple Jump. Korean Journal of Sport Biomechanics, 14, 65-81. http://dx.doi.org/10.5103/KJSB.2004.14.1.065 